\title{
Gene Expression Profiles of HeLa Cells Impacted by Hepatitis C Virus Non-structural Protein NS4B
}

\author{
Yi Zheng, Lin-bai Ye*, Jing Liu, Wei Jing, Khalid A. Timani, Xiao-jun Yang, Fan Yang, \\ Wei Wang, Bo Gao and Zhen-hui Wu \\ Key Laboratory of Virology, Ministry of Education, College of Life Sciences, Wuhan University, Wuhan, Hubei, 430072, China
}

Received 17 August 2004, Accepted 1 October 2004

\begin{abstract}
By a cDNA array representing 2308 signal transductionrelated genes, we studied the expression profiles of HeLa cells stably transfected by Hepatitis $\mathrm{C}$ virus nonstructural protein 4B (HCV-NS4B). The alterations of the expression of four genes were confirmed by real-time quantitative RTPCR; and the aldo-keto reductase family 1, member C1 (AKR1C1) enzyme activity was detected in HCV-NS4B transiently transfected HeLa cells and Huh-7, a human hepatoma cell line. Of the 2,308 genes we examined, 34 were up-regulated and 56 were down-regulated. These 90 genes involved oncogenes, tumor suppressors, cell receptors, complements, adhesions, transcription and translation, cytoskeletion and cellular stress. The expression profiling suggested that multiple regulatory pathways were affected by HCV-NS4B directly or indirectly. And since these genes are related to carcinogenesis, host defense system and cell homeostatic mechanism, we can conclude that HCV-NS4B could play some important roles in the pathogenesis mechanism of $\mathrm{HCV}$.
\end{abstract}

Keywords: AKR1C1, cDNA microarray, Hepatitis C virus

\section{Introduction}

Hepatitis C virus (HCV) infection is an important public health problem worldwide (NIH conference, 1997) because it is a major cause of chronic hepatitis, cirrhosis, and hepatocellular carcinoma (Gordon et al., 1998; WHO 1999; Farci et al., 2000). Although the infection resolves in $15 \%$ of cases, it becomes chronic in up to $80 \%$ infected individuals. The clinical course of chronic hepatitis $\mathrm{C}$ is highly variable. In about $70 \%$ patients, the disease is mild and stable over several

*To whom correspondence should be addressed.

Tel: 86-27-6875-2372; Fax: 86-27-6876-4763

E-mail: linbaiye@whu.edu.cn; linbaiye@hotmail.com decades; whereas in the remaining $30 \%$, it is more rapidly progressive. $\mathrm{HCV}$-encoded proteins have been identified in in vitro and in vivo systems due to the lack of reliable cell culture (Grakoui et al., 1993; Hahm et al., 1995). Recent research efforts are focusing on the properties and functions of individual $\mathrm{HCV}$ gene product in the interest of unraveling the mechanisms of viral pathogenesis.

The HCV RNA genome, approximately $9.5 \mathrm{~kb}$ in length, encodes a long polyprotein which produces ten discrete proteins by host and viral proteinase. These include core protein $(\mathrm{C})$, envelope proteins (E1, E2), proteinase/helicase, replicase, and other non-structural proteins (NS2 to NS5B) (Bartenschlager and Lohmann, 2000; Rosenberg, 2001). Previous studies suggested that core protein could regulate the growth of hepatocytes by affecting the transcription of cellular protooncogenes and other tumor suppressor genes (Ray et al., 1995 and 1997). In addition, it was reported that the core protein of the HCV-1 strain, in cooperation with Ha-ras, transformed primary rat embryo fiboblasts to have tumorigenic phenotypes (Ray et al., 1996) and induces hepatocellular carcinoma in chimera mice. Some functions of the HCV non-structural proteins are known. The NS2-3 protein, a cis-acting metalloprotease, can autocleavage. The NS3 protein has both proteinase activity, which is involved in processing other non-structural proteins, and helicase activity, including ATPase (Suzich et al., 1993). In addition, NS3 can transform NIH3T3 mouse fibroblast cells, through transfection with NS3 cDNA, to tumorigenic cells in nude mice (Sakamuro et al., 1995), and was regarded as the potential target of HCV treatment (Hsu et al., 2003). The NS4A protein is a cofactor for NS3 proteinase (Liu and Rice, 1995) and the NS5B protein has RNA dependent RNA polymerase (RdRp) activity (Hwang et al., 1997; Lohmann et al., 1997; Ferrari et al., 1999). NS4B, a 261-residue hydrophobic peptide, is involved in phosphorylation of NS5A and inhibits cellular protein translation (Koch and Bartenschlager, 1999; Kato et al., 2002 and Egger et al., 2002). NS4B induces a tight structural, designated membranous 
web, consisting of vesicles in a membranous matrix, and associates with the viral replication complex in HCV-infected cells (Egger et al., 2002). Furthermore, NS4B transforms NIH3T3 cells in cooperation with the Ha-ras oncogene (Park et al., 2000). But so far, the function of NS4B protein still remains unclear. As for NS5A protein, it is related with interferon resistance and has attracted much interest due to its antiapoptotic and oncogenic potentials (Tan et al., 1999).

Conventional methods to search for those genes, such as differential display RT-PCR and representational difference analysis, were usually time consuming and limited by the view scope. DNA microarray provides a powerful alternative with an unprecedented view scope in monitoring gene expression levels (Pietu et al., 1996; Dekisi et al., 1997) and leads to discoveries of regulatory pathways involved in complicated biological processes (Dekisi et al., 1996; Chisari, 1997).

In this report, we studied the gene expression profiles of HeLa cells stably transfected by HCV-NS4B using cDNA array to understand potential functions of HCV-NS4B.

\section{Materials and Methods}

Plasmid construction The expression plasmid, pCDNA3.1(-) HCV-NS4B, was constructed by inserting the PCR product of HCV-NS4B region of HCV-k isolate (genotypelb) into the mammalian expression vector pCDNA3.1(-) (Invitrogen, San Diego, USA), which contains human cytomegalovirus (CMV) immediately early promoter. The following primers were synthesized to amplify the HCV-NS4B gene: sense primer: 5'GGATCC TCTAGAACCATGGCTCAGCACTTACCGTAC3' (XbaI digestion site underlined); antisense primer 5'GAATTCAAGCTTTTAGCAT GGAGTGGTACAC3' (HindIII digestion site underlined). The PCR products of HCV-NS4B were digested with XbaI and HindIII and inserted into pCDNA3.1(-) vector by T4 DNA ligase and the recombinant was confirmed by sequencing.

Cell culture HeLa cells were seeded in Dulbecco's Modified Eagle's Medium (DMEM) with $10 \%$ calf serum at a density of $3 \times 10^{5}$ cells per $35 \mathrm{~mm}$ plate. After incubating for $12 \mathrm{~h}$, these cells were transfected with $0.5 \mu \mathrm{g}$ pCDNA3.1(-) in the control group and with pCDNA3.1(-)NS4B in the test group respectively, using the lipofectamine2000 (Life Technologies, GrandIsland, USA). At $24 \mathrm{~h}$ post-transfection, the cells were cultured in $1 \mathrm{mg} / \mathrm{ml} \mathrm{G} 418$ until drug-resistant colonies appeared. Huh-7 cells were seeded in DMEM containing $10 \%$ calf serum at a density of $3 \times 10^{5}$ cells per $35 \mathrm{~mm}$ plate. After incubating for $24 \mathrm{~h}$, the cells were transfected transiently with $1.0 \mu \mathrm{g}$ pCDNA3.1(-) in the control group and with pCDNA3.1(-)NS4B in the test group, using the lipofectamine2000 (Life Technologies, Grand Island, USA). At $48 \mathrm{~h}$ post-transfection, the cells were harvested for later analyses.

RT-PCR for detecting HCV-NS4B mRNA Total RNA was isolated using Trizol reagent (Invitrogen) from the control and test cells. Approximately $2 \mu \mathrm{g}$ RNA from each cell line was used for a reverse transcription polymerase chain reaction (RT-PCR), which was performed using random primers $\mathrm{p}(\mathrm{dN}) 9$ and Moloney murine leukemia virus (MMLV) $\mathrm{H}$ minus reverse transcriptase at $50^{\circ} \mathrm{C}$ for $1 \mathrm{~h}$. Subsequently, cDNA was amplified under the conditions of $94^{\circ} \mathrm{C}, 5 \mathrm{~min} ;\left(94^{\circ} \mathrm{C}, 45 \mathrm{~s} ; 57^{\circ} \mathrm{C}, 45 \mathrm{~s} ; 72^{\circ} \mathrm{C}, 1 \mathrm{~min}\right) 35$ cycles; $72^{\circ} \mathrm{C}$, $10 \mathrm{~min}$.

Immunoblot analysis of HCV-NS4B Stable transfectants and pCDNA3.1(-)NS4B transiently transfected Huh-7 cells were tested for expression of the HCV NS4B protein by immunoblot analysis using HCV-NS4B monoclonal antibody (gifted by Prof. Luo, Kentucky University). $3 \times 10^{7}$ cells were harvested and washed once with $1 \times$ PBS. The cell pellets were resuspended in $200 \mu \mathrm{l}$ lysis buffer $(100 \mathrm{mM} \mathrm{NaCl}, 20 \mathrm{mM}$ Tris-CL, pH 7.5, $1 \mathrm{mM}$ EDTA, $0.5 \%$ TritonX-100 and $1 \mathrm{mM}$ PMSF). The proteins were separated by SDS-PAGE (12\%) and electrophoretically blotted onto a polyvinylidene difluoride filter (PVDF; Bio-Rad, Richmond, USA). The primary and secondary antibody binding was carried out in PBS containing 5\% nonfat dry milk for $1.5 \mathrm{~h}$ and $1 \mathrm{~h}$, respectively. The filters were washed for three times $(10 \mathrm{~min}$ each) after the primary and secondary antibody binding. The protein bands were visualized on Amersham Hyper-Max films by the ECL chemiluminescence system, as recommended by the manufacturer (Amersham, Richmond, USA).

Microarray DNA analysis Total RNA of transfectants were extracted as described in protocol of TRIzol Reagent-Total RNA isolation reagent kit (Invitrogen, San Diego, USA). Poly(A+) RNA were prepared from $200 \mu \mathrm{g}$ total RNA by following part of the protocols (mRNA isolation from cell culture) of polyA-tract system 1000 (Promega, Madison, USA). Fluorescent cDNA probes were prepared from $3 \mu \mathrm{g}$ of each poly (A+) RNA sample using AtlasTM class Fluorescent labeling kit (Clontech, Palo Alto, USA) and cy $3 / 5$ dyes (Amersham pharmacia, Uppsala, USA). Fluorescent probes were hybrized to the microarray slide (Biostar) signal transduction. After hybridization at $65^{\circ} \mathrm{C}$ overnight, non-specific binding probes were washed away and the slide was dried by centrifugation, then scanned by a ScanArray 4000 Scanner. The cy 3 and cy 5 fluorescent intensities of each spot were analyzed by QuanArray software. And the signal intensity of each spot was corrected by subtracting background signals in the immediate surrounding. Not all cDNA probes were hybrized to the target. Our criterion for selecting a cDNA in the analyses was that the fluorescent signal exceeded the background by 3 standard deviations. Because the levels of expression of some housekeeping genes were also changed, for the normalization of data we averaged intensities of all spots obtained with cy 3 and cy5 in each of the DNA spot as the average intensity ratio cy $5 /$ cy $3=1.0$. The criterion for inclusion of a cDNA in a group as either induced or repressed expression was whether balanced differential expression was greater than 2.5 in either direction. If cy $3 /$ cy5 $>2.5$, the gene was considered to be repressed; and if cy $5 /$ cy $3>2.5$, the gene was considered to be induced. The experiment was repeated once.

Quantitative RT-PCR We carried out real-time quantitative PCR to quantify the mRNA levels and the copy numbers of four genesAKR1C1, interleukin 10 receptor, alpha (IL10RA), neuronal pentraxin 1 (NPTX1) and adaptor-related protein complex (AP1)-in HeLa cells stably transfected and Huh-7 cells transiently transfected 
by plasmid pCDNA3.1(-)NS4B and pCDNA3.1(-) according to microarray results. To quantify mRNA levels, we prepared singlestrand cDNA using the same method as the DNA microarray analysis. We checked the RT-PCR products on $2.5 \%$ agrose gel and verified that each product had a single band. We carried out an identical reaction without the reverse transcriptase to verify the absence of genomic DNA. The relative ratio was calculated for each sample in quadruplicate.

Preparation of cell extracts and enzyme analyses HeLa and Huh-7 cells were transiently transfected by plasmids pCDNA3.1(-) HCV-NS4B and pCDNA3.1(-) in different concentrations. Cells were scraped off from the plate with a rubber policeman and collected as a suspension in $1 \mathrm{ml}$ PBS. The cells were harvested by centrifugation $\left(5,000 \times g, 5 \mathrm{~min}, 4^{\circ} \mathrm{C}\right)$ and resuspended in $\sim 200 \mu \mathrm{l}$ of $50 \mathrm{mM}$ Tris-HCL (pH 8.0), containing $150 \mathrm{mM} \mathrm{NaCL}$ and $1 \%$ $(\mathrm{v} / \mathrm{v})$ Ipegal (sigma). Lysates were prepared by subjecting the resuspended cells to three consecutive freeze-thaw cycles: this was achieved by placing the microfuge tube alternately in liquid nitrogen and in a $37^{\circ} \mathrm{C}$ water bath for about $15 \mathrm{~s}$ in each step. Finally, cell debris was removed by centrifugation $(11,000 \times g$, $10 \mathrm{~min}, 4^{\circ} \mathrm{C}$ ). The resulting supernatant was collected and stored at $-70^{\circ} \mathrm{C}$ for later analyses. Protein levels in cell extracts were determined by the method of Bradford using BSA to calibrate the assay. AKR1C1 activity was measured in a reaction mixture containing $0.2 \mathrm{mM} \mathrm{NADP}{ }^{+}$in $\mathrm{NaOH}$-glycine buffer $[25 \mathrm{mM}$ glycine and $4.4 \mathrm{mM} \mathrm{NaOH}(\mathrm{pH} 9.0)]$ together with $1 \mathrm{mM} 1-$ acenaphthenol as the substrate. The AKR-catalyzed reduction of $\mathrm{NADP}^{+}$at $25^{\circ} \mathrm{C}$ was followed at $340 \mathrm{~nm}$ (OConnor et al., 1999).

\section{Results}

Establishment of stable cell lines To study the function of HCV-NS4B protein, we established stable HeLa cell lines transfected by pCDNA3.1(-)-NS4B. We also used HeLa cells containing pCDNA3.1(-) as a control. Results of RT-PCR (data not shown) and Western blot analysis (Fig. 1) showed that stable HeLa cell lines that could express HCV-NS4B protein were established.

Establishment of the cDNA array system We obtained a DNA slide that represented 2308 signal transduction-related genes or cDNA clusters from Biostar company (Shanghai). The reproducibility of the cDNA array analysis was evaluated in multiple replicated tests using cDNA probes independently made from the same mRNA samples to cDNA arrays of different batches. The results of the replicated experiments were almost perfectly concordant with R2 (square of Pearson correlation coefficiency, measuring similarity in gene expression pattern) of 0.94 0.96 (data not shown). Only $0.4 \%$ of the 2308 genes had an expression level in the second measurement 2 fold higher than that in the first measurement. Thus the cDNA array system was highly reproducible.

Expression profiling revealed some differentially expressed genes in HeLa cells transfected by pCDNA3.1(-)NS4B and

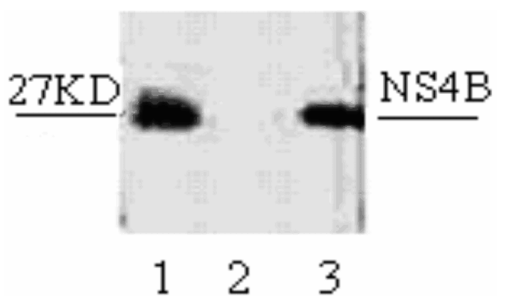

Fig 1. Expression of HCV-NS4B protein examined by immunoblot analysis. Cells lysates from cells transfected by pCDNA3.1(-) NS4B (lane 1, HeLa cells; lane 3, Huh-7 cells) and HeLa cells by pCDNA3.1(-) (lane 2).

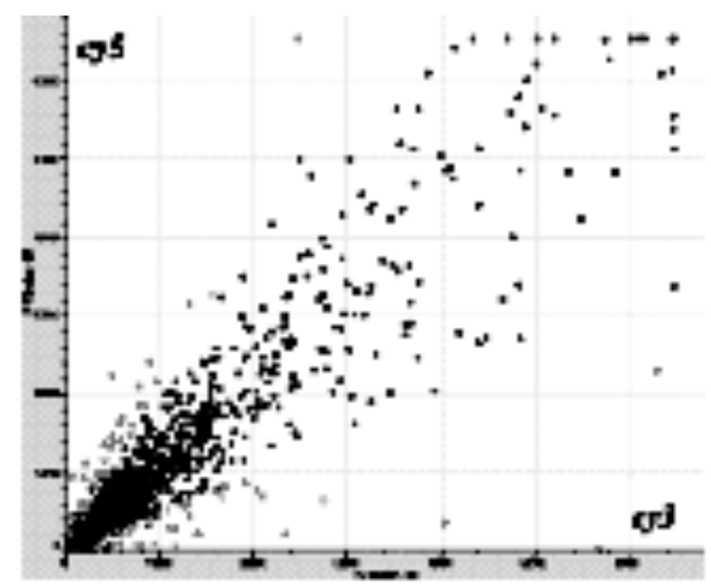

Fig 2. Scatter plots with Imagene 3.0 software after hybridization, cells transfected by pCDNA3.1(-)NS4B(Cy5)/cells transfected by pCDNA3.1(-)(Cy3).

pCDNA3.1(-) (Fig. 2). By a cDNA array representing 2308 signal transduction-related genes, we observed the expression profiling of HeLa cells caused by HCV-NS4B directly or indirectly. Among 90 genes, whose expression has changed by more than 2.5 fold, 34 genes are up-regulated and 56 genes are down-regulated. In those 34 up-regulated genes, the expression of NPTX1 changes up to 14.44 fold. The expression of Dickkopf homolog 1 (DKK1), syndecan 1 (SDC1) and AP1 change over 5 fold. The 10 genes downregulated most dramatically are AKR1C1, IL10RA, substance $\mathrm{K}$, transforming growth factor, beta 1 (TGF- $\beta$ ), leukemia inhibitory factor receptor (LIFR), $\mathrm{H}$ factor (complement)-like 3 (HFL3), fibronectin 1 (FN1), adducin 3 (gamma) (ADD3), carboxypeptidase E (CPE) and dihydropyrimidinase-like 3 (DPYSL3). The expression of these genes changes more than 8 fold. We classified the differentially expressed genes into seven functional groups in table 2 and 3 . These groups are: 1) tumorassociated 2) cytokines, receptors, adhesions and complement 3) transcription and translation associated 4) kinase and phosphatase 5) cellular stress 6) cytoskeleton 7) others.

To confirm the altered expression levels, four selected genes (two up-regulated genes, AP1 and NPTX1, and two 


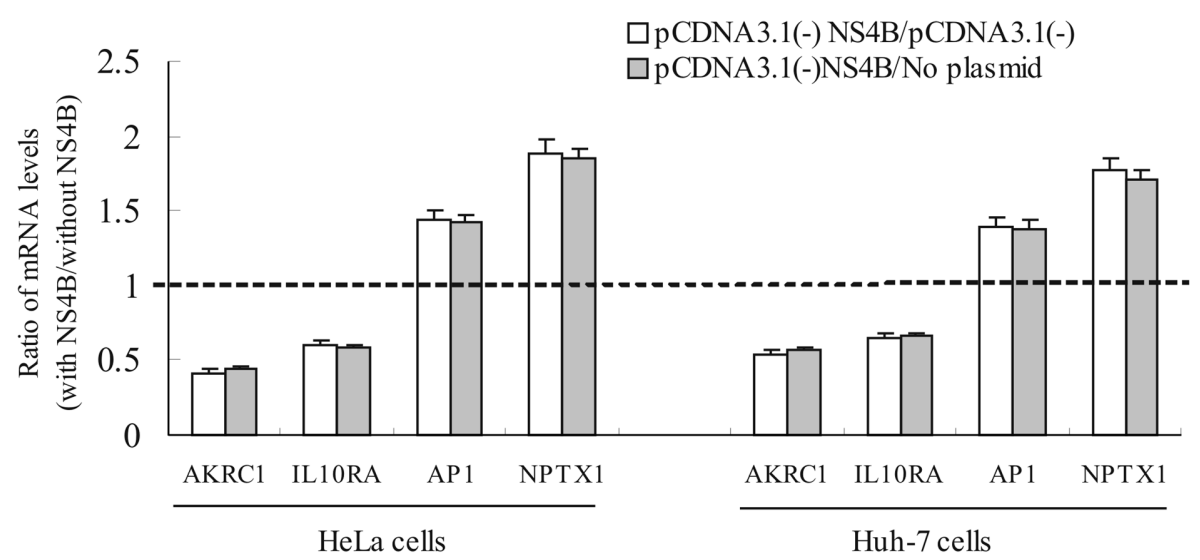

Fig 3. Effects on mRNA levels of the four genes in HeLa and Huh-7 cells transfected by pCDNA3.1(-)NS4B or pCDNA3.1(-). The mRNA levels were normalized to that of GAPDH and the ratio of the levels is shown (values are mean s.e.m.) (a) HeLa cells; (b) Huh7 cells. We confirmed that AKR1C1, IL-10RA, AP1 and NPTX1 expression levels in HeLa and Huh-7 cells affected by HCV-NS4B using real-time quantitative PCR were consistent with those in microarray analysis.

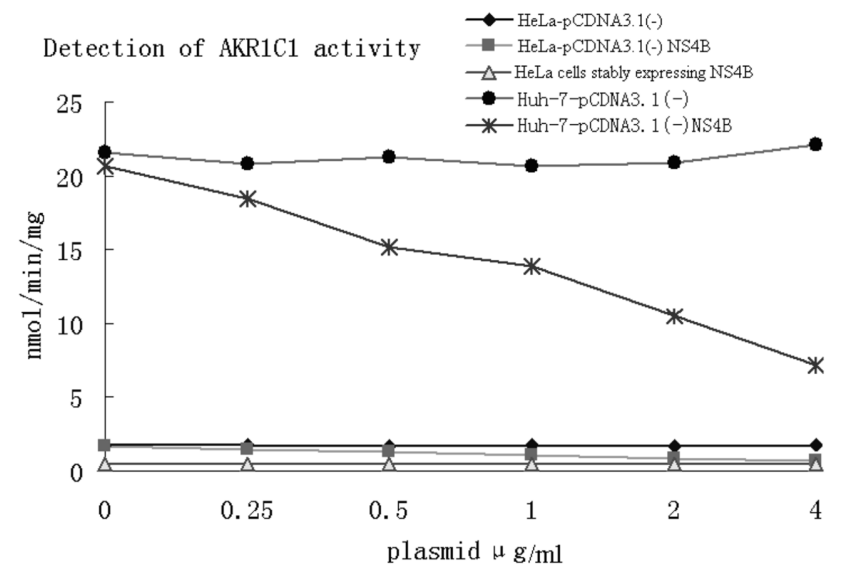

Fig 4. Detection of AKR1C1 enzyme activity. HeLa and Huh7 cells were transiently transfected by either pCDNA3.1(-) or pCDNA3.1(-) NS4B in different concentration (except the stable HeLa cells expressing NS4B proteins). Assays were carried out using substrates at a concentration of $1 \mathrm{mM}$ at standard assay conditions.

down-regulated genes, AKR1C1 and IL10RA) were tested by quantitative RT-PCR. We examined the expression levels of these four genes in pCDNA3.1(-)NS4B transfected, pCDNA3.1(-) transfected, and nontransfected HeLa/Huh-7 cells. The results showed that expression patterns by microarray were consistent with those by RT-PCR (Fig. 3). The results from microarray using HeLa cell line provided some clues to study the functions of HCV-NS4B protein in hepatocytes. The AKR1C1 mRNA is aboundant in Huh-7 cells.

To further verify the results, we chose AKR1C1 and detected its activity in the lysate of HeLa cells stablely expressed NS4B, and in HeLa and Huh-7 cells transiently transfected by pCDNA3.1(-)HCV-NS4B and pCDNA3.1(-). The AKR1C1 enzyme activity in cell lysates is showed in Fig. 4. The activity of HeLa and Huh-7 cells transiently transfected by pCDNA3.1(-)NS4B decreased with the increasing of plasmid concentration, whereas the pCDNA3.1(-) transfected cells did not. Moreover, the activity of AKR1C1 was lowest in HeLa cells stably expressing NS4B protein. It showed that NS4B protein decreased the expression level of AKR1C1.

\section{Discussion}

Although HCV-NS4B protein has been discussed in some reports (Koch and Bartenschlager, 1999; Park et al., 2000; Egger et al., 2002; Kato et al., 2002), its function remains unclear. DNA microarray technology provides an opportunity to survey transcription modulation in the context of an infectious disease and is a particularly attractive approach in characterizing $\mathrm{HCV}$-host interactions. In this report, the expression of NS4B in HeLa cells was confirmed by RT-PCR and Western blot analysis. Then we used cDNA microarray to study the function of NS4B protein. 2308 signal transduction pathway related genes were chosen, among which 34 genes were up-regulated and 56 were down-regulated. Our data indicated that RAP1 (member of RAS oncogene family), FYN oncogene, and DKK1 were up-regulated; whereas some tumor suppressor genes, such as slit homolog 2 (SLIT2), ribonucletide reductase M1 polypeptide (RRM1), tumor protein p53-binding protein (TP53BP) and deleted in colorectal carcinoma (DCC), were down-regulated. Whereas neogein (NEO1), a DCC-related gene was up-regulated. FYN oncogene, which is related with SRC, FGR and YES, might play a role in the carcinogenesis of HCV-NS4B. On the other hand, N-myc downstream regulated gene1, v-fos, and TU3A were down-regulated. Since the development of hepatocellular carcinoma caused by $\mathrm{HCV}$ is a long-term process, which usually takes more than 20 years, it is possible to postulate that this is a complex oncogene and tumor-suppressor gene in interaction process. HCV-NS4B was just one of the multiple 
Table 1. Primers for quantitative RT-PCR and main parameters

\begin{tabular}{|c|c|c|c|}
\hline Gene name & & primer & gene size \\
\hline \multirow[t]{2}{*}{ IL10RA } & sense & 5'CAGGGTGGCTCGGCCTT3' & $336 \mathrm{bp}$ \\
\hline & anti-sense & 5'CAAGGCGAGGAGTGACC3' & \\
\hline \multirow[t]{2}{*}{ AKR1C1 } & sense & 5'GTCCGACCAGCCTTGG3' & $429 \mathrm{bp}$ \\
\hline & anti-sense & 5'CCTCCAAGAGCACCGG3' & \\
\hline \multirow[t]{2}{*}{ AP1 } & sense & 5'GCCTCCCTGGTGTACTCC3' & $436 \mathrm{bp}$ \\
\hline & anti-sense & 5'AGCTCGAAGAGCACGCGG3' & \\
\hline \multirow[t]{2}{*}{ NPTX1 } & sense & 5'GGTGCTGTCCCGGGTG3' & $294 \mathrm{bp}$ \\
\hline & anti-sense & 5'AAGGGCGTGCCCACAC3' & \\
\hline \multirow[t]{2}{*}{ GADPH } & sense & 5'ATCACTGCCACCCAGAAGAC3' & 446 bp \\
\hline & anti-sense & 5'ATGAGGTCCACCACCCTGTT3' & \\
\hline
\end{tabular}

factors required for carcinogenesis and had a weak oncogenic activity that was sufficient to stimulate only a part of a complex multi-step pathway.

Our data showed that NS4B inhibited the expression of many cytokines, receptors and complements, such as transforming growth factor (TGF), leukemia inhibitory factor receptor (LIFR), EphA2, interleukin 10 receptor (IL-10R), interleukin 7 receptor (IL-7R), interferon gamma receptor (IFNGR) and complement including complement component 3 (C3), $\mathrm{H}$ factor and substance $\mathrm{K}$. IFN- $\alpha$, in combination with ribavirin, is currently in part effective on treatment of some patients with HCV. Bigger reported that using DNA microarray analysis of Chimpanzee liver during acute resolving $\mathrm{HCV}$ infection, the most notable changes in gene expression occurred in numerous interferon response genes (including all three classical interferon antiviral pathways) (Bigger et al., 2001). The clearance is associated with elevations in expression of IFN-gamma and TNF-alpha and a measurable increase in T-cell markers in the liver (Guiditti et al., 1999; and Keskinen et al., 2002). NS4B decreased the expression of IFNGR, which may be the reason why we failed to treat hepatitic $\mathrm{C}$ and the early phase of virus clearance. This is consistent with another report (Keskinen et al., 2002) demonstrating that NS4B protein expression alone showed a weak effect, whereas other HCV non-structural proteins did not inhibit IFN-mediated antiviral response (Li et al., 2003). Additionally, the data showed that Janus kinase 2 (JAK2) and MEK kinase 1 (MEKK1) were down-regulated, and NS4B protein could damage the JAK-STAT pathway, which is closely related to the production of IFN. Dual specificity phosphatase 1 (DUSP1), which specifies a protein with structural features similar to members of the non-receptortype protein-tyrosine phosphatase family and has significant amino-acid sequence similarity to the Tyr/Ser-protein phosphatase, was up-regulated. DUSP1 specifically inactivates mitogen-activated protein (MAP) kinase in vitro, and further suppresses the activation of MAP kinase by oncogene Ras, which involved in product of IFN (Kittlesen, 2000; Imasato et al., 2002). HCV core inhibits TNF- $\alpha$-mediated apoptosis through a mechanism that involves interactions with the TNF- $\alpha$ receptor (Tai et al., 2000; Steel et al.; 2001). TNF- $\alpha$ is a major inflammatory cytokine secreted by activated macrophages and T-cells, which play a central role in acute infections. TNF- $\alpha$ stimulates FAS-mediated apoptosis and facilitates clearance of infected cells. Down-regulation of TNF- $\alpha$ receptor would result in the survival of infected hepatocytes and thereby promote persistent HCV infection. IL-10R is structurally related to interferon receptors. It mediates the immunosuppressive signal of interleukin 10, and thus inhibits the synthesis of proinflammatory cytokines. The expression of tissue inhibitor of metalloproteinase 1 (TIMP1), similar to that of IL-10R, is repressed, whereas that of matrix metalloproteinase 1 (MMP-1) is induced. The levels of Complement $\mathrm{C} 3, \mathrm{~S}$ and $\mathrm{K}$ are down-regulated. Block has systematically compared the proteomes of serum of individuals chronically infected by $\mathrm{HCV}$ as a function of their disease status (Steel et al., 2001). The unfolding pattern discovered suggestes that various liver-derived polypeptides decline in amount as disease progresses. The pattern includes complements, apolipoprotein isoforms and haptoglobins. We postulate that HCV-NS4B might inhibit some signal pathways of the hosts defense network and clearance of infected cells according to our microarray data analysis.

NS4B protein could influence the transcription and translation levels of some host genes. It was reported that NS4B protein suppressed translation in vivo (Florese et al., 2002). NS4B protein localizes in the endoplasmic reticulum, on which the translation takes place. Elevated expression was also observed in genes such as zinc finger protein 177 (ZFP177), which modulates transcription and translation efficiency, methyl-CpG binding domain protein 4, translation initiation factor (IF2) and ribosomal protein L29 (RPL29). Reduced expressions of genes were also observed including translation initiation factor (IF3), single-strand DNA binding protein 2 (SSBP2) and helicase with zinc finger domain (HELZ), a member of RNA helicase. In vitro, NS4B is a negative regulator of NS3 which possesses ATPase and helicase activity, preventing it from modulating NS5B RdRp activity (Piccininni et al., 2002). The components of ribosome were observed either up- or down-regulated. They might be 
Table 2. up-regulated genes (Functions indicated for the 34 genes with official names that were up-regulated, were summaried) from http://www.ncbi.nlm.nih.gov/Genbank

\begin{tabular}{|c|c|c|c|}
\hline $\begin{array}{l}\text { Category } \\
\text { accession }\end{array}$ & Gene name & $\begin{array}{l}\text { average } \\
\text { ratio }\end{array}$ & Function \\
\hline \multicolumn{4}{|c|}{ Tumor associated } \\
\hline NM002884 & RAP1A, member of RAS oncogene family & 2.725 & oncogene \\
\hline NM002035 & Follicular lymphoma variant translocation & 2.533 & partopate in the tumoral process \\
\hline NM002885 & RAP1, GTPase activating protein 1(RAP1) & 3.090 & inhibits proliferation \\
\hline ВC015055 & FYN oncogene related to SRC, FGR, YES & 4.524 & oncogene \\
\hline NM012242 & Dickkopf homolog 1 (xenopus laevis )(DKK1) & 5.993 & $\begin{array}{l}\text { the control of emdryonic development and neoplas- } \\
\text { tic process }\end{array}$ \\
\hline \multicolumn{4}{|c|}{ Cytokines, complements, adhesions and receptor } \\
\hline NM004431 & EphA2(EphA2) & 2.676 & mediate developmental events \\
\hline NM007098 & Catenin & 4.885 & associated Wnt pathway \\
\hline NM002436 & Member protein, palmitoglated & 3.506 & associated with the cytoskeleton \\
\hline NM002499 & Neogenin homolog 1 & 3.829 & -- \\
\hline NM000638 & Vitronectin & 4.360 & $\begin{array}{l}\text { cell adhesion and spreading and inhibit the mem- } \\
\text { brane damage }\end{array}$ \\
\hline NM007098 & Clathrin & 4.885 & the main structural protein of the polyhedral lattice \\
\hline NM002997 & Syndecan 1 (SDC1) & 5.159 & a receptor for the extracellular matrix \\
\hline \multicolumn{4}{|c|}{ Transcription and translation } \\
\hline NM003071 & SWI/SNF related, matrix associated & 2.574 & associated with chromatin structure \\
\hline NM000993 & Ribosomal protein L31 (RPL31) & 2.571 & a component of the $60 \mathrm{~S}$ subunit \\
\hline NM003925 & Methyl CpG binding domain protein 4 (MBD4) & 2.699 & binding to methylated DNA \\
\hline U85658 & Transcription factor ERF-1 & 3.079 & a member of the AP2 transcription factor \\
\hline NM006298 & Zinc finger protein 177 (ZNF177) & 4.135 & modulate transcription and translation efficiency \\
\hline \multicolumn{4}{|c|}{ Kinase ,phosphatase and adaptor } \\
\hline NM032454 & Serine/threonine kinase 19 (STK19) & 2.573 & -- \\
\hline NM004417 & Dual specificity phosphatase 1 (DUSP1) & 4.456 & suppress the activation of MAP kinase \\
\hline NM005498 & Adaptor related protein complex 1 & 5.029 & interacting with tyrosine based sorting signals \\
\hline \multicolumn{4}{|c|}{ Cellular- stress } \\
\hline NM004528 & Microsomal glutathine S-transferase 3 & 2.863 & $\begin{array}{l}\text { drug metabolism and synthesis of cholesterol and } \\
\text { liquda }\end{array}$ \\
\hline NM003846 & Peroxisomal biogenesis factor IIB & 2.941 & oxidative stress \\
\hline NM001673 & Asparagine synthetase (ASNS) & 4.567 & related to ATF2 \\
\hline \multicolumn{4}{|l|}{ Cytoskeleton } \\
\hline NM003794 & Sorting nexin 4 (SNX4) & 2.654 & involved in intercellular trafficking \\
\hline NM053024 & Profilin 2 (PFN2) & 3.148 & regulate actin polymerization \\
\hline NM001313 & Collapsing response mediator protein 1 & 3.345 & a invasion-suppresor \\
\hline NM003980 & Microtubule-associated protein 7 (MAP7) & 4.713 & modulate microtubule functions \\
\hline \multicolumn{4}{|l|}{ Others } \\
\hline NM006528 & Tissue factor pathway inhibitor (TFPI) & 3.730 & the binding to ox-LDL \\
\hline NM000602 & Serine (or cysteine) proteinase inhibitor & 3.363 & -- \\
\hline NM003451 & Zinc finger protein $177(\mathrm{ZNF} 192)$ & 3.010 & $\begin{array}{l}\text { member of a new subclass of the Kruppel gene fam- } \\
\text { ily }\end{array}$ \\
\hline NM019025 & Chromosome 20 open reading frame 16 & 3.516 & -- \\
\hline NM002522 & Neuronal pentraxin (NPTX1) & 14.444 & a member of the neuronal pentraxin gene family \\
\hline AL117490 & CDNA DKFp434N211 & 2.576 & -- \\
\hline NM003870 & IQGAP1 & 2.595 & cell motility and invasion \\
\hline
\end{tabular}

involved in the inhibition of protein synthesis by NS4B. Some components of ribosome expression had significant differences in hepatocellular carcinoma compared with normal tissue using cDNA microarray (Okabe et al., 2001). Our data demonstrated that methyl-CpG binding protein (MBD) was up-regulated, which the main epigenetic modification of the human genome is methylated by cytosine residues within the context of the $\mathrm{CpG}$ dinucleotides (Maio et al., 2002). 
Table 3. down-regulated genes(Functions indicated for the 56 genes with official names that were down-regulated, were summaried) from http://www.ncbi.nlm.nih.gov/Genbank

\begin{tabular}{|c|c|c|c|}
\hline $\begin{array}{l}\text { Category } \\
\text { accession }\end{array}$ & Gene name & $\begin{array}{l}\text { average } \\
\text { ratio }\end{array}$ & Function \\
\hline \multicolumn{4}{|c|}{ Tumor associated } \\
\hline NM006096 & N-myc downstream regulated gene1 (NDRG1) & 0.265 & putative metastatic suppressor \\
\hline NM005252 & v-fos FBJ murine osteosarcinoma viral oncogene & 0.267 & regutors of cell differentiation and transformation \\
\hline NM004529 & myeloid/lymphoid or mixed lineage leukemia & 0.286 & associated with Leukemia \\
\hline NM007177 & TU3A protein (TU3A) & 0.307 & -- \\
\hline NM002048 & Growth arrest-specific 1(GAS1) & 0.311 & putative tumor suppressor \\
\hline NM000617 & Slit homolog 2(SLIT2) & 0.365 & tumor suppressor \\
\hline NM005802 & Tumor protein p53-binding protein (TP53BP) & 0.382 & binding to $\mathrm{p} 53$ protein \\
\hline NM005215 & Deleted in colorectal carcinoma (DCC) & 0.389 & tumor suppressor \\
\hline \multicolumn{4}{|c|}{ Cytokines, complements and receptors } \\
\hline NM000358 & Transforming growth factor, beta-induced & 0.081 & associated with fibrosis \\
\hline NM002310 & Leukemia inhibitory factor receptor (LIFR) & 0.088 & receptor of LIF \\
\hline NM005666 & $\mathrm{H}$ factor (complement)-like 3(HFL3) & 0.109 & serum protein related to complement factor $\mathrm{H}$ \\
\hline NM003182 & Tachykinin, precursor1 (substance K) & 0.109 & immune regulatory activities within CNS \\
\hline NM001558 & Interleukia 10 receptor, alpha (IL10RA) & 0.111 & inhibits the synthesis of proinflammatory cytokines \\
\hline D50683 & TGF-beta II R alpha & 0.146 & associated with fibrosis \\
\hline NM006206 & Platelet-derived growth factor receptor(PDGFRA) & 0.169 & a cell surface tyrosine kinase receptor \\
\hline NM002185 & Interleukia 7 receptor (IL7R) & 0.199 & a receptor for IL-7 \\
\hline NM003467 & Chemokine (C-X-C motif ), receptor & 0.219 & A coreceptor with CD4 for HIV-1 \\
\hline NM002260 & Killer cell lectin-like receptor subfamily $\mathrm{C}$ & 0.214 & the regulation of NK cell function \\
\hline NM000064 & Complement component 3 (C3) & 0.320 & $\begin{array}{l}\text { A central role in the activation of complement sys- } \\
\text { tem }\end{array}$ \\
\hline NM000416 & Interferon gamma receptor 1 (IFNGR1) & 0.355 & the ligand-binding chain of IFNR \\
\hline NM000576 & Interleukin 1, beta (IL1B) & 0.359 & cell proliferation, differentiation, and apoptosis \\
\hline NM004356 & CD81 antigen & 0.399 & regulation of develoption, activation, growth \\
\hline NM003236 & Transforming growth factor, alpha & 0.375 & associated with fibrosis \\
\hline NM002508 & Nidogen (NID) & 0.197 & component of basement membrane zones \\
\hline Y10183 & MEMD protein & 0.247 & A new cell adhesion molecule \\
\hline \multicolumn{4}{|c|}{ Transcription and translation } \\
\hline NM021141 & $\begin{array}{l}\text { x-ray repair complementing defective repair } \\
\text { (XRCC5) }\end{array}$ & 0.150 & ATP-dependant DNA helicase or DNA repair protein \\
\hline AJ223333 & putative DNA methylotransferase & 0.383 & associated with DNA methyl- transfer \\
\hline NM014877 & helicase with zinc finger domain (HELZ) & 0.384 & a member of RNA helicase \\
\hline NM001268 & chromosome condensatin1-like (CHC1) & 0.400 & -- \\
\hline NM003752 & eukaryotic translation initiation factor 3 & 0.395 & associated with translation \\
\hline \multicolumn{4}{|c|}{ Kinase } \\
\hline NM004972 & Janus kinase 2 (JAN2) & 0.299 & a member of JAK family \\
\hline AF042838 & MEK kinase 1 (MEKK1) & 0.367 & A member of MAPK pathway \\
\hline \multicolumn{4}{|c|}{ Cellular -stress } \\
\hline NM001353 & Aldo-keto reductase family 1 , member $\mathrm{C} 1$ & 0.003 & catalyze the conversion of aldehydes and ketones \\
\hline NM005053 & RAD23 homolog A & 0.377 & nucleotide repair and ubiquitin-mediated pathway \\
\hline $\begin{array}{l}\text { NM000104 } \\
\text { cytoskeleton }\end{array}$ & Cytochrome P450, subfamily 1 & 0.389 & biotransformation of many drugs \\
\hline NM002026 & Fibronectin 1 (FN1), transcript variant 1 & 0.086 & regulator of extracellular matrix organization \\
\hline NM016824 & Adducin 3 (gamma) (ADD3) & 0.123 & belong to a family of membrane skeletal protein \\
\hline NM007317 & Kinesin like 4 (KNSL4) & 0.294 & microtubule-dependant molecule motors \\
\hline \multicolumn{4}{|c|}{ others } \\
\hline NM000176 & Nuclear receptor subfamily 3 , group C & 0.282 & glucocortocoid receptor \\
\hline NM004504 & HIV-1 REV binding protein (HRB) & 0.359 & mediates nucleocytoplasmic transport \\
\hline NM001873 & Carboxypeptidase E (CPE) & 0.106 & -- \\
\hline
\end{tabular}


Table 3. Continued

\begin{tabular}{clll}
\hline $\begin{array}{c}\text { Category } \\
\text { accession }\end{array}$ & \multicolumn{1}{c}{ Gene name } & $\begin{array}{c}\text { average } \\
\text { ratio }\end{array}$ & \multicolumn{1}{c}{ Function } \\
\hline NM001871 & Carboxypeptidase B1 (CPB1) & 0.183 & a useful serum marker for acute pancreatitis \\
M92303 & Voltage-dependant calcium channel beta-1 & 0.234 & associated with Ca transfer \\
NM006820 & Potassium voltage-gated channel & 0.344 & a member of potassium channel \\
NM000927 & ATP-binding cassette, subfamily B & 0.301 & an ATP-dependant drug efflux pump \\
NM000824 & Glycine receptor, beta (GLRB) & 0.303 & receptor of Glycine \\
NM002073 & Guanine nucleotide binding protein & 0.341 & a member of a G protein subfamily \\
NM006820 & Chromosome 1 open reading frame 29 & 0.346 & -- \\
AK026463 & FLJ22810fis & 0.355 & -- \\
NM001387 & Dihydropyrimidinase-like 3 (DPYSL3) & 0.102 & -- \\
NM000677 & Adenosine A3 receptor (ADORA3) & 0.166 & against injury \\
AL512688 & CDNA DKFZp 547J2313 & 0.169 & -- \\
AF104032 & L-type amino acid transporter subunit LA & 0.230 & L-type amino acid transporter \\
NM000617 & Solute carrier family 11 & 0.362 & proton-coupled divalent metal ion transporters \\
NM005142 & Gastric intrinsic factor & 0.373 & Vitamin B synthesis \\
NM005950 & Metallothionein 1 G(MT1G) & 0.392 & binds various heavy metals \\
\hline
\end{tabular}

Furthermore, hypoacetylation of histones is frequently associated with $\mathrm{CpG}$ island hypermethylation, together with results in a compact structure of chromatin, which is repressive in transcription. It is also reported that $\mathrm{HCV}$ may self-limit the amount of viral protein. Our data support this hypothesis based on the above results.

Elevated expression was observed in Nexin, plasmygen activator inhibitor type1 (PAI), membrane protein, palmitoylated1 (MPP1), tissue factor pathway inhibitor2 (TFPI2), vitronectin, and syndecan-1(SDC1). PAI appears to stabilize the chemoattractant form of IL-8 at the cell surface, prevents shedding of proteoglycan, and maintains the chemoattractant gradient. Our data showed that IL-8 was weakly up-regulated. Syndecan, a cell surface proteoglycan, is an integral membrane protein acting as a receptor on the extracellular matrix. It mediates hepatocyte growth factor binding and promotes Met signaling in multiple myeloma. Promoted Met signaling was also seen in hepatocellular carcinoma. Vitronectin is a member of the pexin family that promotes cell adhesion and spreading, inhibits the membranedamaging effect of terminal cytolytic complement pathway, promotes the survival of infected cells, and leads to persistent infection by binding to several serpin serine protease inhibitors. In our data, the expression level of serine/cysteine proteinase was up-regulated. TFPI, an inhibitor of the extrinsic coagulation system, was activated in liver cancer patients and may reduce fibrin formation (Iversen et al., 1998). Inactivation or repression of it by drug intervention may slow the progression of hepatic cancer. Profilin 2 is a ubiquitous actin monomer-binding protein belonging to the profiling family, regulating actin polymerization in response to extracellular signals. MMP1 is the prototype of a family of membrane-associated proteins termed membrane associated guanylate kinase homolog1 (MAGUKs). MAGUKs interact with the cytoskeleton and regulate cell proliferation, signaling pathways and intracellular junctions. Collapsin response mediator protein1 (CRMP1) has a role in RhoA-dependent signaling through interaction with and regulation of Rokalpha. CRMP1 is defined by human dihydropyrimidinase, which is down-regulated by HCV- NS4B protein.

In this report, the expression levels of the genes related to cellular stress also changed. Microsomal glutathine Stransferase 1 (MGST1), RAD22 and cytochrome P450 were down-regulated; but microsomal glutathine S-transferase 3 (MGST3) and peroxisomal biogenesis factor IIB were upregulated. These genes are detoxifying genes. Though these enzymes play an important part in the oxidative breakdown of toxic compounds under normal conditions, and lead to the free radical injury of intracellular macromolecules, a process that can promote hepatocellular carcinogenesis. AKR1C1 was dramitically down-regulated in both HeLa cells and Huh-7 cells by HCV-NS4B protein. However, the pathological role of AKR1C1 inhibited by HCV-NS4B protein remains unknown. RAD23 homolog A is involved in DNA repair and inhibits degradation of specific substrates in response to DNA damage. Recently, it is discovered that RAD23 (Laar et al., 2002) also associates with png1p, a deglycosylation enzyme, which is important in ER-associated protein degradation after malfolded proteins accumulate in the endoplasmic reticulum. Asparagine synthetase (ASNS), a gene also related with ERstress, was elevated. It is discovered that HCV subreplicons could induce IRE1-XBP1 expression; but XBP1 transactivation activity is repressed (Tardif et al., 2004). HCV-E2 and NS4B have influence on the expression of IRE1-XBP1 (data not shown). Viruses such as HCV and HBV, which use the ER as an integral part of their replication strategy, must contend with the ER stress response and downstream consequences of ER stress signaling. ER stress is a homeostatic mechanism that 
regulates cellular metabolism and protein synthesis in response to perturbations in protein folding and biosynthesis (Ma and Hendershot, 2001). Mild ER stress modulates protein synthesis initiation and slow down cell growth, but extreme or prolonged ER stress is associated with caspase 12 and cause cell apoptosis (Kaufman, 1999). In addition, many transcription factors are induced by ER stress (Gass et al., 2002). The relation of NS4B-induced membranous web with ER-stress needs to study further. HCV and other flaviviruses are shown to induce ER stress (Jordan et al., 2002). While apoptosis is one extreme outcome of virus-induced ER stress, noncytopathic viruses like $\mathrm{HCV}$, which induce ER stress signaling at sublethal levels, is likely to cause alterations in cell physiology that can lead to cellular transformation. The long-term consequences of low-level ER stress signaling on the pathogenesis of HCV infection are not well understood, but it is hypothesized that persistent stress induction that results in intracellular and extracellular accumulation of DNA damaging factors could predispose a cell to mutagenesis.

In conclusion, highthroughput microarray analysis used in this study permitted the simultaneous analysis of changes that occurred in HeLa cells affected by HCV-NS4B protein. Though the genes we analyzed represented only a small subset of human genome, our conclusive data suggested that HCV-NS4B might be important in $\mathrm{HCV}$ pathogenesis, persistence and carcinogenesis. In this report, we used HeLa cells instead of liver cells. Though HeLa cell line could only partly reflect the results in hepatocytes affected by NS4B protein, the change of expression levels in the four genes we examined and in the enzyme activity of AKR1C1 were consistent with that in Huh-7 cells transiently transfected by HCV-NS4B. Future work needs to focus on genes expressing specifically in hepatocytes based on our DNA microarray results.

Acknowledgments We thank Professor Guangxiang Luo (Kentucky University) for HCV-NS4B monoclonal antibody and Professor Jinrong Gao (Wuhan University) for help.

\section{References}

Bartenschlager, R. and Lohmann, V. (2000) Replication of hepatitis C virus. J. Gen. Virol. 81, 1631-1648.

Bigger, C. B., Brasky, K. M. and Lanford, R. E. (2001) DNA microarray analysis of chimpanzee liver during acute resolving hepatitis C virus infection. J. Virol. 75, 7059-7066.

Chisari, F. V. (1997) Cytotoxic T cells and viral hepatitis . J. Clin. Investig. 99, 1472-1477.

Dekisi, J. L., Lyer, V. R. and Brown, P. O. (1997) Exploring the metabolic and genetic control of gene expression on a genomic scale. Science 273, 680-686.

Dekisi, J. L., Penland, L., Brown, P. O., Bittner, M. L., Meltzer, P. S., Ray, M. C. Y., Su, Y. A. and Trent, J. M. (1996) Use of a cDNA microarray to analyse gene expression patterns in human cancer. Nat. genet. 14, 457-460.
Egger, D., Walk, B., Gosert, R., Bianchi, L., Blum, H. E., Moradpour, D. and Bienz, K. (2002) Expression of hepatitis C virus proteins induces distinct membrane alterations including a candidate viral replication complex. J. Virol. 76, 5974-5984.

Farci, P., Shimoda, A., Coiana, A., Diaz, G., Peddis, G., Melpolder, J. C., Strazzera, A., Chien D. Y., Munoz, S. J., Balestrieri, A., Purcell, R. H. and Alter, H. J. (2000) The outcome of acute hepatitis $\mathrm{C}$ predicted by the evolution of the viral quasispecies. Science 288, 399-342.

Ferrari, E., Wright-Minogue, J., Fang, J. W. S., Baroudy, B. M., Lau, J. Y. N. and Hong, Z. (1999) Characterization of soluble hepatitis $\mathrm{C}$ virus RNA-dependent RNA polymerase expression in Escherichia coli. J. Virol. 73, 1649-1654.

Florese, R. H., Motoko, N. F., Iwanaga, Y., Hidajat, R. and Hotta, H. (2002) Inhibition of protein synthesis by nonstructural proteins NS3, NS4A and NS4B. Virus Res. 90, 119-131.

Gass J. N., Gifford, N. M. and Brewer J. W. (2002) Activation of an unfold protein response during differentiation of antibodysecreting B cells. J. Biol. Chem. 277, 49047-49054.

Gordon, S. C., Bayati, N. and Silverman, A. L. (1998) Clinical outcome of hepatitis $\mathrm{C}$ as a function of mode of transmission. Hepatology 28, 562-567.

Grakoui, A., Wychowshi, C., Lin, C., Feinstone, S. M. and Rice, C. M. (1993) Expression and identification of hepatitis C virus polyprotein cleavage products. J. Virol. 67, 1385-1395.

Guiditti, L. G., Rochford, R. Chung, J., Shapri, M., Purcell, R. and Chisari, F. V. (1999) Viral clearance without destruction of infected cells during acute HBV infection. Science. 284, 825829.

Hahm, B., Han, D. S., Back, S. H., Song, O. K, Cho, M. J., Shimotone, K. and Jang, S. K. (1995) NS3-4A of hepatitis C virus is a chymotrypsin-like protease. J. Virol. 69, 2534-2539.

Hsu, E. C., Hsi, B., Masami, T. H., Jurgen, R., Cathy, I., Farida, S., Diao, J. Y., Giovanni, M., Lorne, T. D., Norman, K. and Richardson, C. D. (2003) Modified apoptotic molecule (BID) reduces hepatitis $\mathrm{C}$ virus infection in mice with chimeric human livers. Nature Biotechnol. 21, 19-525.

Hwang, S. B., Park, K. J., Kim, Y. S., Sung, Y. S. and Lai, M. M. C. (1997) Hepatitis C virus NS5B protein is a membraneassociated phosphoprotein with a predominantly perinuclear localization. Virology 227, 439-446.

Imasato, A., Desbois-Mouthon, C. Han, J., Kai, H., Cato, A. C., Akira, S. and Li, J. D. (2002) Inhibition of p38 MAPK by glucocorticoids via induction of MAPK phosphatase-1 enhances nontypeable Haemophilus influenzae-induced expression of toll-like receptor2. J. Biol. Chem. 277, 4744447450.

Iversen, N., Lindahl, A. K. and Abildgaard, U. (1998) Elevated TFPI in malignant disease: relation to cancer type and hypercoagulation. British J. Haematol. 102, 889-895.

Jordan R., Nikolaeva, O., Wang L., Conyers B., Mehta A., Dwek R. A. and Block T. M. (2002) Inhibition of host ER glucosidase activity prevents Golgi processing of virionassociated bovine viral diarrhea virus E2 glycoprotein and reduces infectivity of secreted virions. Virology 295, 10-19.

Kato, J., Kato, N. Y., Yoshida, H., Nita, S. K. O., Shiratori, Y. and Omata, M. (2002) Hepatitis C virus NS4A and NS4B proteins suppress translation in vivo. J. Med. Virol. 66, 187-199.

Kaufman, R. J. (1999) Stress signaling from lumen of the endoplasmic reticulum: coordination of gene transcriptional and 
translational controls. Genes Dev. 13, 1211-1233.

Keskinen, P., Melen, K. and Julkunan I. (2002) Expression of $\mathrm{HCV}$ structural protein impairs IFN-mediated antiviral response. Virology 299, 164-171.

Kittlesen D. J. F., Chianese-Bullock, K. A. F., Yao, Z. Q. F., Braciale, T. J. F. and Hahn, Y. S. (2000) Interaction between complement receptor $\mathrm{gClqR}$ and hepatitis $\mathrm{C}$ virus core protein inhibits T-lymphocyte proliferation. J. Clin. Invest. 106, 12391249

Koch, J. O. and Bartenschlager, R. (1999) Modulation of hepatitis $\mathrm{C}$ virus NS5A hyperphosphorylation by nonstructural proteins NS3, NS4A and NS4B. J. Virol. 73, 7138-7146.

Laar, T. V., Van der, E. A. J. and Terleth, C. (2002) A role for Rad 23 proteins in $26 \mathrm{~S}$ proteasome-dependent protein degradation. Mutat. Res. 499, 53-61.

Li, M., Zhou, J. Y., Ge, Y., Matherly, L. H. and Wu, G. S. (2003) The phosphatase MKP1 is a transcriptional target of p53 involved in cell cycle regulation. J. Biol. Chem. 278, 4105941068.

Liu, C. and Rice, C. M. (1995) Hepatitis C virus NS3 serine proteinase and NS4A cofactor: establishment of a cell-free trans-processing assay. Proc. Natl. Acad. Sci. USA 92, 76227626.

Lohmann, V., Korner, F., Herian, V. and Bartenschlager, R. (1997) Biochemical properties of hepatitis C virus NS5B RNAdependent RNA polymerase and identification of amino acid sequence motifs essential for enzymatic activity. J. Virol. 71, 8416-8428.

Ma, Y. and Hendershot, L. M. (2001) The unfolding tale of the unfolded protein response. Cell 107, 827-830.

Maio M., Coral, S., Fratta, E., Altomonte, M. and Sigalotti, L. (2003) Epigenetic targets for immune intervention in human malignancies. Oncogene 22, 6484-6488.

National Institutes of Health Consensus Development Conference Panel Statement: Management of Hepatitis C. (1997) Hepatology 26, 2S-10S.

OConnor, T., Ireland, L. S., Harrison, D. J. and Hayes, J. D. (1999) Major differences in the function and tissue-specific expression of human aflatoxin B1 aldehyde reductase (AFAR) and the principal human aldo-keto reductase AKR1 family members. Biochem. J. 343, 487-504.

Okabe, H., Satoh, S., Kato, T., Kitahara, O., Yanagawa, R., Yamaoka, Y., Tsunoda, T., Furakawa, Y. and Nakamura, Y. (2001) Genome-wide analysis of gene expression in human hepatocellular carcinoma using cDNA microarray: Identificationof genes involved in viral carcinogenesis and tumor progression. Cancer Res. 61, 2129-2137.

Park, J. S., Yang, J. M. and Min, M. K. (2000) Hepatitis C virus nonstructural protein NS4B transforms NIH3T3 cells in cooperation with the Ha-ras oncogene. Biochem. Biophys. Res. Commun. 267, 581-587.
Piccininni, S., Varaklioti, A., Nardelli, M., Dave, B., Raney, K. D. and McCarthy, J. E. (2002) Modulation of the hepatitis C virus RNA-dependant RNA polymerase activity by the non-structural (NS3) helicase and the NS4B membrane protein. J. Biol. Chem. 227, 45670-45679.

Pietu, G., Alibert, O., Guichard, V., Lamy, B., Bois, F., Leroy, E., Mariage-Sampson, R., Soularue, P. and Auffray, C. (1996) Novel gene transcripts preferentially expressed in human mucles revealed by quantitative hybridization of a high density cDNA array. Genome Res. 6, 492-503.

Ray, R. B., Meyer, K., Steele, R. and Ray, R. (1997) Transcriptional repression of $\mathrm{p} 53$ promoter by hepatitis $\mathrm{C}$ virus core protein. J. Biol. Chem. 272, 10983-10986.

Ray, R. B., Lagging, L. M., Meger, K., Steele, R. and Ray, R. (1995) Transcriptional regulation of cellular and viral promoters by the hepatitis C virus core protein. Virol. Res. 37, 209-220.

Ray, R. B., Lagging, L. M., Meyer, K. and Ray, R. (1996) Hepatitis $\mathrm{C}$ virus core protein cooperates with ras and transforms primary rat embryo fibroblasts to tumorigenetic phenotype. J. Virol. 70, 4438-4443.

Rosenberg, S. (2001) Recent advances in the molecular biology of hepatitis C virus. J. Mol. Biol. 313, 451-464.

Sakamuro, D., Furukawa T. and Takegami T. (1995) Hepatitis C virus non-structural protein NS3 transform NIH3T3 cells. $J$. Virol. 69, 3893-3896.

Steel, L. F., Mattu, T. S., Mehta, A., Hebestreit, H., Dwek, R., Evans, A. A., London, W. T. and Block, T. (2001) A proteomic approach for the discovery of early detection markers of hepatocellular carcinoma. Dis. Marker. 17, 179-189.

Suzich, J. A., Taura, J., Palmer-Hill, F., Warrenger, P., Grakoui, A., Rice, C. M., Feinstone, S. M. and Collett, M. S. (1993) Hepatitis C virus NS3 protein plynucleotide-stimulated nucleoside triphosphatase and comparison with the telated Pestivirus and Flavivirus enzymes. J. Virol. 67, 6152-6158.

Tai, D., Tsai, S., Chen, Y., Chuang, Y., Peng, C., Yeh, C., Chang, K. S. S., Huang, S., Kuo, G. C. and Liaw, Y. F. (2000) Activation of nuclear factor $\mathrm{kB}$ in hepatitis $\mathrm{C}$ virus infection: implications for pathogenesis and hepatocarcinogenesis. Hepatology 31, 656-664.

Tan, S. L., Nakao, H., He, Y., Vijaysri, S., Neddermann, P., Jacobs, B. L., Mayer, B. J. and Kaze, M. G. (1999) NS5A, a nonstructural protein of hepatitis $\mathrm{C}$ virus, binds growth factor receptor-bound protein 2 adaptor protein in Src homology 3 domain/ligand-dependent manner and perturbs mitogenic signaling. Proc. Natl. Acad. Sci. USA 96, 5533-5538.

Tardif, K. D., Mori, K., Kaufman, R. and Siddiqui, A. (2004) Hepatitis $\mathrm{C}$ virus suppresses the IRE1-XBP1 pathway of the unfolded protein response. J. Biol. Chem. 279, 17158-17164.

World Health Organization. (1999) Global surveillance and control of hepatitis C. J. Viral. Hepat. 6, 35-47. 